\title{
PENENTUAN KUALITAS FISIKA (WARNA, SUHU, DAN TDS) DARI SAMPEL AIR SUMUR WARGA DI KECAMATAN DUMAI TIMUR
}

\author{
Yelfira Sari ${ }^{1 *}$, Arief Yandra Putra ${ }^{2}$, Anasthasia Oca Muham ${ }^{3}$ \\ ${ }^{1,2,3}$ Program Studi Pendidikan Kimia, Universitas Islam Riau \\ ${ }^{*}$ Corresponding author. \\ *Email: yelfirasari@edu.uir.ac.id; Phone number: +62-813-7859-3394
}

\begin{abstract}
Abstrak
Kualitas air dapat diketahui dengan melakukan pengujian tertentu terhadap air tersebut. Pengujian yang biasa dilakukan adalah pengujian kualitas fisika, kimia, dan biologi. Dalam penelitian ini, pengujian yang dilakukan berupa pengujian kualitas fisika yaitu dengan mengukur warna, suhu, dan TDS. Penentuan warna sampel air dilakukan secara langsung melalui pengamatan menggunakan indera penglihatan, sedangkan untuk pengukuran suhu dan TDS sampel air menggunakan alat berupa thermometer dan TDS-meter. Sampel air yang digunakan dalam penelitian ini diambil dari 5 kelurahan yang terdapat di Kecamatan Dumai Timur, yaitu Kelurahan Bukit Batrem, Kelurahan Buluh Kasap, Kelurahan Jaya Mukti, Kelurahan Tanjung Palas, dan Kelurahan Teluk Binjai. Sampel air diambil dari sumur-sumur rumah warga yang dipilih secara acak, dimana pada masing-masing kelurahan diambil 5 sampel. Sampel air tersebut diperiksa kualitasnya yang didasarkan pada baku mutu Menteri Kesehatan dalam Peraturan Menteri Kesehatan No : 416/MEN.KES/PER/IX/1990. Hasil penelitian ini menunjukkan bahwa semua sampel air yang terdapat di Kecamatan Dumai Timur tidak layak secara parameter fisika, karena sampel air tersebut berwarna, dimana berdasarkan baku mutu, air dikatakan layak jika tidak berbau, berwarna, dan berasa.
\end{abstract}

Kata kunci : Kualitas air, parameter fisika, warna, suhu, TDS

\begin{abstract}
Water quality can be determined by doing certain test. Common parameter for determination water quality was physical, chemical, and biological parameter. This research was determined physical parameter, such as water colour, temperature, and TDS. Water colour determination was using eyesight sense while for temperature and TDS using a tool, thermometer for temperature determination and TDS-meter for TDS determination. Samples were taken from 5 Kelurahan in Dumai Timur District, that is Kelurahan Bukit Batrem, Kelurahan Buluh Kasap, Kelurahan Jaya Mukti, Kelurahan Tanjung Palas, and Kelurahan Teluk Binjai. Samples was taken from citizen wells which was selected in random as many as 5 samples for each Kelurahan. Water quality from samples was measured based on Regulation of Minister for Public Health No:416/MEN.KES/PER/IX/1990. Result of this research showed that all of water sample from Dumai Timur District were improper in physical parameter because of the water were turbid.
\end{abstract}

Keywords : Water quality, physical parameter, colour, temperature, TDS

\section{Pendahuluan}

Berdasarkan studi literatur yang telah dilakukan terlebih dahulu, ternyata masih banyak daerah di Indonesia yang langka akan air bersih. Padahal air adalah suatu sarana utama dalam meningkatkan derajat kesehatan masyarakat. Jika air yang digunakan oleh masyarakat bebas dari kandungan bahan-bahan yang berbahaya dan tidak 
mengganggu kesehatan, air tersebut dianggap bersih dan layak untuk dikonsumsi. Sedangkan jika terdapat gangguan terhadap kualitas air, air tersebut dikatakan telah tercemar sehingga tidak dapat digunakan untuk tujuan penggunaannya (Mifbakhuddin 2010).

Kecamatan Dumai Timur adalah salah satu kecamatan dengan jumlah penduduk terbanyak di Kota Dumai. Kondisi tanah di Kota Dumai mayoritas berupa tanah rawa yang bergambut dengan kedalaman antara 0-0,5 m. Tanah ini umumnya bersifat sangat asam dengan warna cokelat cenderung kehitaman. Berdasarkan kondisi tanahnya tersebut, kualitas air di daerah Dumai sangat jauh dari baku mutu yang telah ditetapkan oleh pemerintah.

Berdasarkan data yang diperoleh dari Dinas Kesehatan Kota Dumai Tahun 2015, diketahui bahwa penggunaan air sumur sebagai sumber air bagi masyarakat sekitar 47 $\%$. Sedangkan persentase penduduk yang memiliki akses air minum berkualitas atau layak sekitar $18 \%$. Bila dibandingkan dengan target sasaran tahun 2015 sebesar $70 \%$, maka pencapaian angka tersebut belum memenuhi target (Kementerian Kesehatan 2016).

\section{Metode}

Pengambilan sampel dilakukan di Kecamatan Dumai Timur. Teknik pengambilan sampel menggunakan teknik purposive sampling. Sampel diambil pada masing-masing kelurahan yang terdapat di Kecamatan Dumai Timur, dimana kecamatan ini memiliki 5 kelurahan yaitu Kelurahan Bukit Batrem, Kelurahan Buluh Kasap, Kelurahan Jaya Mukti, Kelurahan Tanjung Palas, dan Kelurahan Teluk Binjai.

Penelitian ini menggunakan metode kuantitatif. Pengumpulan data dilakukan dengan melakukan pemeriksaan di laboratorium terhadap parameter kandungan air tanah. Adapun parameter yang diuji adalah parameter fisika berupa pengukuran suhu, warna, dan TDS (zat padatan terlarut). 


\section{Hasil dan Pembahasan}

\section{Pengambilan Sampel}

Sampel dalam penelitian ini diambil dari 5 kelurahan yang terdapat di Kecamatan Dumai Timur, yaitu Kelurahan Bukit Batrem, Kelurahan Buluh Kasap, Kelurahan Jaya Mukti, Kelurahan Tanjung Palas, dan Kelurahan Teluk Binjai. Sampel air sumur diambil dari rumah-rumah warga yang dipilih secara acak, dimana pada masing-masing kelurahan diambil 5 sampel. Sampel air tersebut diperiksa kualitasnya berdasarkan parameter fisika serta parameter kimia yang didasarkan pada baku mutu Menteri Kesehatan dalam Peraturan Menteri Kesehatan No : 416/MEN.KES/PER/IX/1990.

\section{Penentuan Kualitas Air Berdasarkan Parameter Fisika}

Parameter fisika yang diuji kualitasnya adalah warna, suhu, dan zat padatan terlarut (TDS). Pengukuran parameter ini langsung dilakukan di lokasi pengambilan sampel. Penentuan warna dilakukan dengan cara pengamatan menggunakan indra penglihatan sedangkan pengukuran suhu dan TDS dilakukan menggunakan alat ukur berupa termometer dan TDS-meter.

\section{Warna}

Tabel 1 Penentuan Kualitas Warna Sampel Air

\begin{tabular}{|c|c|c|c|c|c|c|}
\hline \multirow[b]{2}{*}{$\begin{array}{c}\text { Titik } \\
\text { Sampling }\end{array}$} & \multirow[b]{2}{*}{ Baku Mutu } & \multicolumn{5}{|c|}{ Kelurahan } \\
\hline & & $\begin{array}{l}\text { Buluh } \\
\text { Kasap }\end{array}$ & $\begin{array}{c}\text { Bukit } \\
\text { Batrem }\end{array}$ & Jaya Mukti & Teluk Binjai & $\begin{array}{c}\text { Tanjung } \\
\text { Palas }\end{array}$ \\
\hline 1 & & $\begin{array}{l}\text { Tidak } \\
\text { berwarna }\end{array}$ & Cokelat & Kecokelatan & $\begin{array}{l}\text { Kuning } \\
\text { keruh }\end{array}$ & $\begin{array}{l}\text { Cokelat } \\
\text { gelap }\end{array}$ \\
\hline 2 & & $\begin{array}{l}\text { Tidak } \\
\text { berwarna }\end{array}$ & & Keruh & $\begin{array}{l}\text { Cokelat } \\
\text { terang }\end{array}$ & Keruh \\
\hline 3 & $\begin{array}{c}\text { Tidak } \\
\text { berwarna }\end{array}$ & $\begin{array}{l}\text { Tidak } \\
\text { berwarna }\end{array}$ & $\begin{array}{l}\text { Tidak } \\
\text { berwarna }\end{array}$ & Cokelat & $\begin{array}{l}\text { Tidak } \\
\text { berwarna }\end{array}$ & $\begin{array}{l}\text { Cokelat } \\
\text { gelap }\end{array}$ \\
\hline 4 & & Putih susu & Kecokelatan & Cokelat & $\begin{array}{l}\text { Sedikit } \\
\text { kuning }\end{array}$ & $\begin{array}{l}\text { Kuning } \\
\text { keruh }\end{array}$ \\
\hline 5 & & $\begin{array}{l}\text { Tidak } \\
\text { berwarna }\end{array}$ & $\begin{array}{l}\text { Tidak } \\
\text { berwarna }\end{array}$ & $\begin{array}{l}\text { Cokelat } \\
\text { gelap }\end{array}$ & $\begin{array}{l}\text { Tidak } \\
\text { berwarna }\end{array}$ & Kecokelatan \\
\hline
\end{tabular}

Warna pada air dapat disebabkan oleh adanya bahan organik, bahan anorganik, ion-ion logam seperti logam Fe, serta bahan-bahan lainnya (Munfiah and Setiani 2013). Keberadaan logam Fe yang sangat tinggi di dalam air dapat menyebabkan perubahan warna pada air tersebut, dari bening menjadi kuning hingga kecokelatan. Air ini jika 
digunakan untuk mencuci maka akan meninggalkan noda cokelat kemerahan pada pakaian. Selain itu, air ini juga akan meninggalkan bekas pada dinding-dinding bak penampungan dan kamar mandi (Rasman and Saleh 2016) (Kementerian Kesehatan RI 2011).

Dari Tabel 1 dapat dilihat bahwa rata-rata air sumur di Kecamatan Dumai Timur keruh dan cenderung kecokelatan. Dari 5 kelurahan yang ada, hanya satu kelurahan yang air sumurnya tidak berwarna, empat kelurahan lainnya ada yang berwarna kuning, merah, bahkan cokelat. Hal ini tidak sesuai dengan syarat air bersih yang telah ditetapkan oleh pemerintah, yaitu tidak berasa, tidak berbau, dan tidak berwarna.

\section{Suhu}

Suhu air yang baik menurut baku mutu yang telah ditetapkan dalam PerMenKes No. 416 Tahun 1990 adalah $25 \pm 3^{\circ} \mathrm{C}$. Suhu air yang tidak sesuai dengan baku mutu meunjukkan indikasi adanya bahan kimia terlarut dalam jumlah yang cukup besar atau sedang terjadi proses dekomposisi bahan organik oleh mikroorganisme (Mairizki 2017). Suhu memiliki pengaruh yang besar terhadap kelarutan oksigen, semakin tinggi suhu air, kandungan oksigen di dalam air tersebut akan semakin berkurang (Ningrum 2018). Berdasarkan Tabel 2, dapat dilihat bahwa suhu sampel air di beberapa kelurahan di Kecamatan Dumai Timur masih tidak sesuai dengan baku mutu dan hal ini berarti air tersebut tidak layak untuk dikonsumsi.

Tabel 2 Pengukuran Suhu Air

\begin{tabular}{c|c|c|c|c|c|c}
\hline \multirow{2}{*}{$\begin{array}{c}\text { Titik } \\
\text { Sampling }\end{array}$} & \multirow{2}{*}{ Baku Mutu } & \multicolumn{5}{|c}{ Kelurahan } \\
\cline { 3 - 6 } & $\begin{array}{c}\text { Buluh } \\
\text { Kasap }\end{array}$ & $\begin{array}{c}\text { Bukit } \\
\text { Batrem }\end{array}$ & Jaya Mukti & Teluk Binjai & $\begin{array}{c}\text { Tanjung } \\
\text { Palas }\end{array}$ \\
\hline 1 & & $29^{\circ} \mathrm{C}$ & $30^{\circ} \mathrm{C}$ & $30^{\circ} \mathrm{C}$ & $32^{\circ} \mathrm{C}$ & $30^{\circ} \mathrm{C}$ \\
2 & $30^{\circ} \mathrm{C}$ & $31^{\circ} \mathrm{C}$ & $29^{\circ} \mathrm{C}$ & $31^{\circ} \mathrm{C}$ & $30^{\circ} \mathrm{C}$ \\
3 & Suhu udara & $30^{\circ} \mathrm{C}$ & $31^{\circ} \mathrm{C}$ & $30^{\circ} \mathrm{C}$ & $30^{\circ} \mathrm{C}$ & $31^{\circ} \mathrm{C}$ \\
4 & $\pm 3^{\circ} \mathrm{C}$ & $31^{\circ} \mathrm{C}$ & $31^{\circ} \mathrm{C}$ & $30^{\circ} \mathrm{C}$ & $30^{\circ} \mathrm{C}$ & $30^{\circ} \mathrm{C}$ \\
5 & & $30^{\circ} \mathrm{C}$ & $31^{\circ} \mathrm{C}$ & $30^{\circ} \mathrm{C}$ & $31^{\circ} \mathrm{C}$ & $31^{\circ} \mathrm{C}$ \\
\hline
\end{tabular}

\section{Zat Padat Terlarut/Total Dissolved Solids (TDS)}


Zat padat terlarut di dalam air biasanya terdiri atas senyawa organik dan senyawa anorganik yang larut dalam air, mineral serta garam-garamnya (Munfiah and Setiani 2013) dan (Ningrum 2018). Salah satu ion yang dapat mempengaruhi keberadaan TDS dalam air adalah ion $\mathrm{Fe}^{2+}$. Air dengan kadar TDS yang tinggi dapat meninggalkan noda dan kerak pada alat-alat rumah tangga serta menghasilkan air dengan rasa yang tidak enak (Sasongko, Widyastuti, and Priyono 2014). Selain itu, dengan semakin tingginya nilai TDS maka akan memberikan dampak negatif terhadap beberapa parameter air lainnya (Amani and Prawiroredjo 2016).

Dari Gambar 1 dapat dilihat bahwa hampir semua sampel air di kelurahan yang terdapat di Kecamatan Dumai Timur memiliki nilai TDS di bawah baku mutu yang telah ditetapkan oleh Menteri Kesehatan. Nilai baku mutu TDS untuk air bersih adalah sebesar $1500 \mathrm{mg} / \mathrm{L}$. Air sumur yang memiliki TDS melebihi baku mutu terletak di Kelurahan Buluh Kasap pada titik sampling 1. Nilai TDS pada titik ini adalah $1640 \mathrm{mg} / \mathrm{L}$.

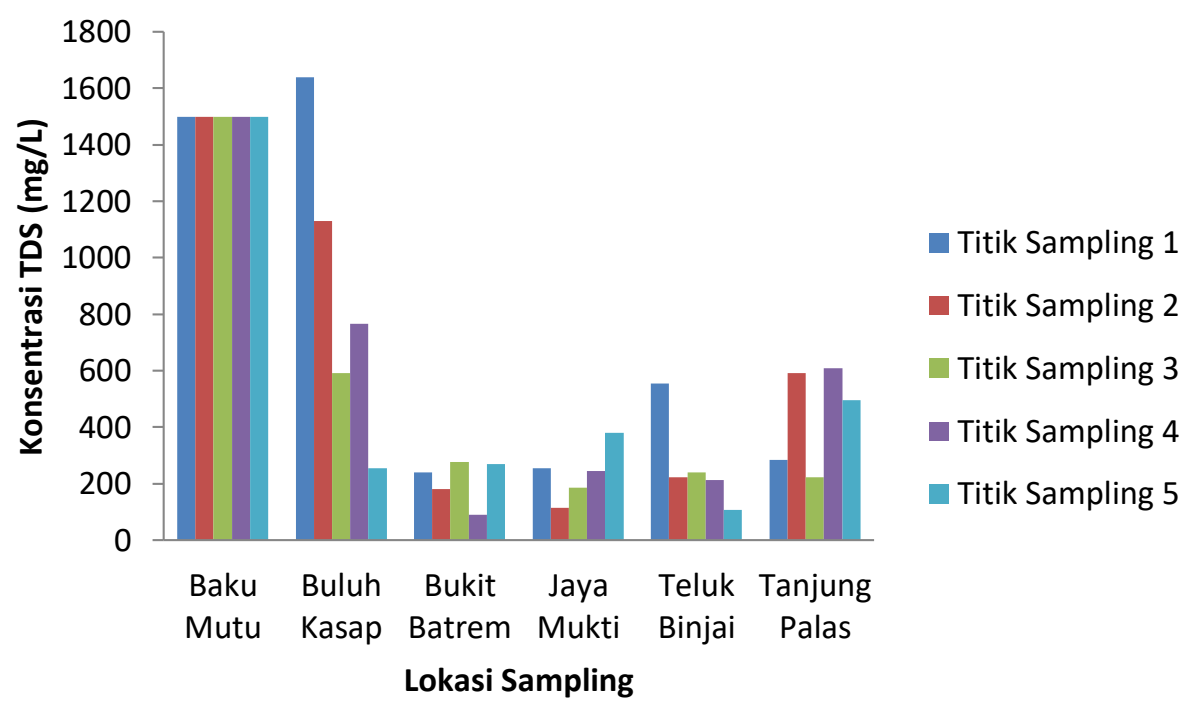

Gambar 1. Konsentrasi TDS pada air sumur di Kecamatan Dumai Timur

\section{Kesimpulan}

Berdasarkan penelitian yang telah dilakukan, dapat disimpulkan bahwa sampel air sumur yang terdapat di Kecamatan Dumai Timur masih tidak layak untuk digunakan baik sebagai air bersih maupun air minum. Air-air ini jika tetap dikonsumsi akan 
memberikan efek negatif terhadap manusia. Air yang memiliki warna keruh bahkan cokelat ini dapat meninggalkan bekas noda yang dapat merusak estetika.

\section{Daftar Referensi}

Amani, Fauzi, and Kiki Prawiroredjo. 2016. "Alat Ukur Kualitas Air Minum Dengan Parameter pH, Suhu, Tingkat Kekeruhan, Dan Jumlah Padatan Terlarut." JETri 14(1): 49-62.

Kementerian Kesehatan. 2016. Profil Kesehatan Tahun 2016.

Kementerian Kesehatan RI. 2011. "Penjernihan Air Dengan Metode Aerasi \& Filtrasi." In Pelatihan Teknologi Tepat Guna Kesehatan Lingkungan, , 1-19.

Mairizki, Fitri. 2017. "Analisis Kualitas Air Minum Isi Ulang Di Sekitar Kampus Universitas Islam Riau." Katalisator 2(1): 9-19.

Mifbakhuddin. 2010. "Pengaruh Ketebalan Karbon Aktif Sebagai Media Filter Terhadap Penurunan Kesadahan Air Sumur Artetis." Eksplorasi 5(2): 1-11.

Munfiah, Siti, and Onny Setiani. 2013. "Kualitas Fisik Dan Kimia Air Sumur Gali Dan Sumur Bor Di Wilayah Kerja Puskesmas Guntur II Kabupaten Demak." Jurnal Kesehatan Lingkungan Indonesia 12(2): 154-59.

Ningrum, Susanti Oktavia. 2018. "Analisis Kualitatif Badan Air Dan Kualitas Air Sumur Di Sekitar Pabrik Gula Rejo Agung Baru Kota Madiun." Jurnal Kesehatan Lingkungan 10(1): 1-12.

Rasman, and Muh Saleh. 2016. "Penurunan Kadar Besi ( Fe ) Dengan Sistem Aerasi Dan Filtrasi Pada Air Sumur Gali ( Eksperimen )." Higiene 2: 159-67. journal.uinalauddin.ac.id/index.php/higiene/article/download/1826/2236.

Sasongko, Endar Budi, Endang Widyastuti, and Rawuh Edy Priyono. 2014. "Kajian Kualitas Air Dan Penggunaan Sumur Gali Oleh Masyarakat Di Sekitar Sungai Kaliyasa Kabupaten Cilacap." Jurnal Ilmu Lingkungan 12(2): 72-82. 